\title{
A mechanistic model for electrical conduction in soil-root continuum: a virtual rhizotron study
}

Sathyanarayan Rao ${ }^{1}$, Félicien Meunier ${ }^{2}$, Solomon Ehosioke ${ }^{3}$, Nolwenn Lesparre ${ }^{4}$, Andreas Kemna $^{5}$, Frédéric Nguyen ${ }^{3}$, Sarah Garré ${ }^{6}$, Mathieu Javaux ${ }^{1,7}$.

${ }^{1}$ Université catholique de Louvain, Earth and Life Institute-Environmental Sciences, Louvain-laNeuve, Belgium

${ }^{2}$ Computational and Applied Vegetation Ecology lab, Ghent University, Gent, Belgium

${ }^{3}$ Applied Geophysics, Université de Liège, Chemin des Chevreuils 1, 4000 Liege, Belgium

${ }^{4}$ Laboratoire d'Hydrologie et Géochimie de Strasbourg, University of Strasbourg/EOST/ENGEES, CNRS UMR 7517, 1 Rue Blessig, 67084 Strasbourg, France

${ }^{5}$ Department of Geophysics, University of Bonn, Meckenheimer Allee 176, 53115 Bonn, Germany

${ }^{6}$ Université de Liège, Gembloux Agro-Bio Tech, TERRA Research and Teaching Center, Passage des déportés 2, 5030 Gembloux, Belgium.

${ }^{7}$ Agrosphere, IBG3, Forschungszentrum Juelich GmbH, Germany

Correspondence to : Mathieu Javaux (mathieu.javaux@uclouvain.be)

\begin{abstract}
Electrical Resistivity Tomography (ERT) has become an important tool to study soil water fluxes in cropped field. ERT results translates to water content via empirical pedophysical relations that take soil physical properties into account, usually ignoring the impact of roots. Studies shows high root dense soils behaves quite differently than less root dense soils in terms of bulk electrical conductivity. Yet, we do not completely understand the impact of root segments on the ERT measurements. In this numerical study, we coupled an electrical model with a plant-soil water flow model to investigate the impact of plant root growth and water uptake on the ERT virtual experiment. The electrical properties of roots were explicitly accounted in the finite element mesh and we obtained the electrical conductivities of root segments by conducting specific experiments on real maize plants. The contrast between electrical conductivity of roots and soil depends on factors such as root density, irrigation, root age, and root water uptake pattern. Root growth and water uptake processes thus affect this contrast together with the soil electrical properties. Model results indicate a non-negligible anisotropy in bulk electrical conductivity induced by root processes. We see a greater anisotropy in a sandy medium when compared to a loamy medium. We find that the water uptake process dominates the bulk electrical properties. The Gauss-Newton type ERT inversion of virtual rhizotron data demonstrate that, when root-soil electrical conductivity contrasts are high, it can lead to error in water content estimates since the electrical conductivity is partly due to root. Thus, incorporating the impact of root in the pedophysical relations is very important to interpret ERT results directly as water content.
\end{abstract}




\section{Introduction}

Understanding root water uptake and associated nutrients is critical for crop management (e.g. Gregory et al. 2005) but remains a challenging task due to the inherent difficulty to collect observations in the soil (e.g. de Dorlodot et al., 2007). Geophysical monitoring of soil-root system water fluxes have received growing interest in the past decades to tackle this challenge. In particular, in this paper, we will particularly investigate the potential of Electrical Resistivity Tomography (ERT) (Michot et al., 2003; Paglis, 2013). This method aims at retrieving the 2D or 3D distribution of the electrical conductivity $(\sigma)$ or its inverse resistivity in the soil. The electrical conductivity is then related to the variable of interest (for instance the soil water content SWC) through a pedophysical or petrophysical relationships.

In cropped fields, ERT method has been increasingly used for monitoring soil water content (SWC) (Beff et al., 2013; Brillante et al., 2016; De Carlo et al., 2015; Garrè et al., 2011; Michot et al., 2003; Srayeddin and Doussan, 2009; Vanella et al., 2018). More recently, ERT-estimated water content was used for phenotyping root systems at field scale (Whalley et al., 2017). The authors monitored changes in $\sigma$ of the soil root zone in drying condition at different soil depths, which acted as a proxy of root activity. However, apparent or bulk conductivity of a vegetated soil (potentially containing roots), denoted by $\sigma_{b u l k}$, is not only dependent to SWC but also to roots and their impact on soil structure. Field experiments further show that the rooted zone soil behaves quite different in terms of pedophysical relation as compared to soil containing no roots (Michot et al., 2016; Werban et al., 2008). Therefore ERT-monitored SWC in agricultural fields can be inaccurate or misleading if we ignore the impact of root-related processes on the bulk conductivity of the soil-root continuum.

In the literature, various studies mention or even target the impact of roots on $\sigma_{\text {bulk }}$. In Fig. 1, we report values of bulk soil electrical conductivity without roots, denoted by $\sigma_{\text {bulk-soil }}$, and root segment electrical conductivity, denoted by $\sigma_{\text {root }}$. The ratio between $\sigma_{\text {root }}$ and $\sigma_{\text {bulk-soil }}$ is generally a function of plant species, soil type, SWC and solute concentration.

For a given species, $\sigma_{\text {root }}$ is a function of root anatomy, which can be related to root age, root order or root diameter. In their study, Anderson and Higinbotham (1976), found that older maize root segments are electrically more conductive than younger roots. Their study was performed on excised root segments. They showed that the outer layer of the root segment (cortex) has very low 
electrical resistance $(\sim 50 \mathrm{k} \Omega)$ in the radial direction when compared to the axial direction $(\sim 600$ $\mathrm{k} \Omega$ ). By treating cortex and stele as concentric parallel conductors, the reported resistances, when converted into conductivity are of the order $\sigma_{\text {root }} \sim 0.05 \mathrm{~S} / \mathrm{m}$. However, the electrical behavior of intact root segments embedded in the soil might be different as compared to excised segments. Another study by Cao et al. (2010) reported that the root electrical resistance could be related to root properties such as surface area, number of lateral roots and root length. Studies on poplar roots show that $\sigma_{b u l k}$ of the soil-root medium may increase or decrease with the increase in root mass density depending on the age of the plant (Al Hagrey, 2007; Zenone et al., 2008). On the other hand, $\sigma_{\text {bulk-soil }}$ depends on several factors, the most important being the porosity of the soil, the electrical conductivity of the soil fluid $\left(\sigma_{w}\right)$, and SWC. In addition, loamy and clayey soils have a surface conductivity that depends on mineral composition, SWC and $\sigma_{w}$ (Friedman, 2005).

Literature on root electrical properties (Anderson and Higinbotham, 1976; Cao et al., 2010, 2011; Ginsburg and Laties, 1973; Paglis, 2013) and pedophysical models for soils (Al Hagrey, 2007; Amente et al., 2000; Bhatt and Jain, 2014; Friedman, 2005; Garrè et al., 2011; Laloy et al., 2011; Werban et al., 2008; Wunderlich et al., 2013) suggest that if the contrast between $\sigma_{\text {root }}$ and $\sigma_{\text {bulk-soil }}$ is large enough, roots could have a measurable impact on ERT inversion results. In addition there are studies that found a correlation between root length/mass density and electrical resistivity obtained from ERT (Amato et al., 2009; Rossi et al., 2011). These studies used destructive methods to determine root length density and root biomass. However, to our knowledge, there are no detailed modeling efforts to study the effects of roots on electrical conductivity of the bulk medium when monitoring SWC in cropped fields using the ERT method.

Beyond the impact of the electrical conductivity of root tissues, root-related processes like water uptake, exudation or solute uptake will also affect the electrical properties of the rhizosphere, i.e. the soil zone in close proximity to root segments, thereby affecting the $\sigma_{\text {root }}-\sigma_{\text {bulk-soil }}$ contrast. The evolution of plant transpiration and root growth will also constantly impact the $\sigma_{\text {root }}$ $\sigma_{\text {bulk-soil }}$ patterns. Recent ERT experiments on orange orchards field suggest that ERT results are more sensitive to root water uptake pattern (Vanella et al., 2018) than the presence of resistive lignified roots. While this may be true for orange trees, we need a thorough study to investigate the sensitivity of ERT result on the presence of different types of root that are more electrically conductive than soil. Therefore, to investigate the impacts of roots on ERT derived SWC, we 
Biogeosciences Discuss., https://doi.org/10.5194/bg-2018-280

Manuscript under review for journal Biogeosciences

Discussion started: 5 July 2018

(c) Author(s) 2018. CC BY 4.0 License.

should take into account the root water uptake, soil heterogeneity, root specific electrical property along with root growth.

To validate and quantify the impact of roots on ERT-derived SWC, we propose to simulate ERT on a virtual soil-root system. Al Hagrey and Petersen (2011) studied the impact of roots on ERT imaging by using a root growth model (Wilderotter, 2003), however they ignored the inherent heterogeneity of $\sigma_{\text {root }}$ and $\sigma_{\text {bulk-soil }}$. To understand the effect of root system connectivity and their impact on SWC on $\sigma_{\text {bulk }}$, a model where roots are explicitly represented is needed. Explicit root representation using unstructured finite element mesh has been studied for water and nutrient uptake processes (Tournier et al., 2015; Wilderotter, 2003), but to the best of our knowledge, no such work exists for ERT simulations coupled to a plant-soil water flow model.

The objective of this study is to investigate how a transpiring growing plant might affect the ERT estimate of SWC. We hypothesize that the $\sigma$ contrast between the plant root system and the soil surrounding the roots (impacted by root, soil properties, and plant hydraulic boundary conditions) together with the amount of roots will affect the ERT measurements and therefore ERT-derived quantities. In our work, we model the electrical conductivity of the soil-root system in a rhizotron geometry with a fine spatial resolution for the roots using an unstructured mesh for the ERT simulation. The root model includes transient transpiration, root growth and root and soil water redistribution. We choose the maize root system for our study and exclude root exudation and solute uptake processes. We also study anisotropy in the electrical conductivity induced by root growth and the water depletion pattern. An accurate electrical conductivity model of the soil-root system will improve our understanding of the electrical behavior of the soil-root zone and hence will help us in improving the ERT method as a feasible and faster tool to monitor soil moisture in vegetated land. This study is therefore a first step towards a thorough understanding of the impact of roots on SWC monitoring using the ERT method.

\section{Materials and Methods}

Our numerical experiment consists in running a combination of highly detailed simulations representing the soil water fluxes in a planted 2-D rhizotron along with an ERT simulation. Root and soil electrical and hydraulic properties were explicitly accounted for and spatially distributed with a high resolution to study how root architecture and water uptake influence the ERT imaging 
results and the interpretation in terms of SWC. Fig. 2 summarizes the various steps described below in a flow diagram.

\subsection{Rhizotron/plant water flow model}

A two-dimensional root architecture was extracted from light transmission experiments on a real rhizotron with a 21 days old maize species using the root image analyzing tool SMARTROOT (Lobet et al., 2011). The digitized root (see Fig.3) was then used for root water uptake modeling using R-SWMS (Javaux et al., 2008). Since the root growth was monitored every day, ages were easily assigned to each root segment. Root growth was simulated by updating the root system architecture at each time step between the beginning (day 5 ) and the end (day 22) of the simulation. Cyclic transpiration demand was imposed as top boundary condition for the root system. The daily transpiration was supposed to linearly increase between the root emergence and the end of the study. At day 22, daily transpiration reached $25 \mathrm{~cm}^{3}$.

The root system is entirely contained in soil box whose length, thickness and depth were $22 \mathrm{~cm}, 1$ $\mathrm{cm}$, and $40 \mathrm{~cm}$ respectively (the corresponding reference axes are $-11<\mathrm{x}<11 \mathrm{~cm},-0.5<\mathrm{y}<0.5 \mathrm{~cm}$, $-40<z<0 \mathrm{~cm}$ ). In the scenario analysis, we considered both sandy and loamy soil types whose hydraulic properties were supposed to be perfectly represented by Mualem-van Genuchten equations (van Genuchten, 1980). Hydraulic parameters for both soils are given in Table 1.

The initial soil condition was a hydrostatic equilibrium with a saturated soil at the bottom of the rhizotron and root transpiration was the only source/sink term that allowed the total water content to change. R-SWMS (Javaux et al., 2008) uses the finite element method on a regular uniform grid to solve Richards equation in order to simulate three-dimensional water flow in the soil:

$$
\frac{\partial \theta}{\partial t}=\frac{\partial}{\partial x}\left(K \frac{\partial h}{\partial x}\right)+\frac{\partial}{\partial y}\left(K \frac{\partial h}{\partial y}\right)+\frac{\partial}{\partial z}\left(K \frac{\partial(h+z)}{\partial z}\right)-\operatorname{Sink}
$$

,where $\theta$ is the volumetric SWC, $h$ the matrix head, $K$ the isotropic hydraulic conductivity, Sink is a sink term for root water uptake $\left[\mathrm{cm}^{3} \mathrm{~cm}^{-3} \mathrm{day}^{-1}\right]$, and $x, y$ and $z$ are the spatial coordinates. Experimentally measured maize root hydraulic conductivities were used in the R-SWMS model, in which they are age and type dependent (Couvreur et al., 2012; Doussan et al., 2006). Twodimensional distributions of roots and of SWC were subsequently transformed into electrical conductivity maps through appropriate bio-pedo electrical relations. 
Biogeosciences Discuss., https://doi.org/10.5194/bg-2018-280

Manuscript under review for journal Biogeosciences

Discussion started: 5 July 2018

(c) Author(s) 2018. CC BY 4.0 License.

\subsection{Electrical properties of plant root tissues and soils}

To get insight into maize root electrical properties, we designed specific experiments on intact root segments (Ehosioke et al., in preparation). First, we identified and separated the primary and brace roots from maize plants grown in laboratory and were thoroughly washed with demineralized water and dried with absorbent tissue. The electrical resistance of root segments was measured using a digital multimeter and were converted into electrical conductivity $\left(\sigma_{\text {root }}\right)$ by approximating the root segment as a cylindrical geometry similar to Cao et al. (2010). The measurement direction of root segments in Cao et al. (2010) is from root apex towards root collar while it is opposite in the case of our experiment. We studied intact root segments as compared to excised root segments in the studies of Cao et al. (2010) or Anderson and Higinbotham (1976) and investigated both primary and brace roots in the experiments. We examined variations of $\sigma_{\text {root }}$ with respect to the segment distance from the root collar and root cross-sectional area with a segment length of $4 \mathrm{~cm}$. Conductivity gel (Rodisonic, from Pannoc Nv/SA Belgium) was used to improve the electrical contact between root segments and measuring electrodes,. However, in the simulation model, only the variations of $\sigma_{\text {root }}$ as a function of segment distance from the root collar is used. The digital maize roots in our simulation are around three weeks old while the brace roots develop only after several weeks in a real maize plant; hence, the brace root data are not included in our model.

To compute soil electrical properties, we used Archie's law (Archie, 1942) with an additional term for surface conductivity of the solid phase $\sigma_{\text {surface }}$, which is assumed to act in parallel (Waxman and Smits, 1968). The relation between soil water content $\theta$ and $\sigma_{\text {soil }}$ for unsaturated soil is given by Eq. 2, where Archie's fitting parameters ( $m$ and $d$ ) vary for different types of soil (Friedman, 2005):

$$
\sigma_{\text {bulk-soil }}=\sigma_{w} n^{m} S^{d}+S^{d-1} \sigma_{\text {surface }}
$$

where, $S$ is the degree of water saturation $\left(S=\frac{\theta}{n}\right), n$ the porosity of soil (assumed to be equal to saturated water content: $\left.\theta_{\mathrm{s}}\right), \sigma_{\text {bulk-soil }}$ the bulk electrical conductivity of the soil medium without considering roots (more specifically, $\sigma_{\text {bulk-loam }}$ for loam and $\sigma_{\text {bulk-sand }}$ for sand), $\sigma_{w}$ the conductivity of soil fluid phase, $\sigma_{\text {surface }}$ is the surface electrical conductivity of the solid phase of the soil. Sand typically has very low surface conductivity $\left(\sim 10^{-5} \mathrm{~S} / \mathrm{m}\right)$ while for loam, we assume $\sigma_{\text {surface }}$ to be $0.015 \mathrm{~S} / \mathrm{m}$ (Brovelli and Cassiani, 2011). For Archie's fitting parameters, we use the 
Biogeosciences Discuss., https://doi.org/10.5194/bg-2018-280

Manuscript under review for journal Biogeosciences

Discussion started: 5 July 2018

(c) Author(s) 2018. CC BY 4.0 License.

typical values $\mathrm{d}=2$ and $\mathrm{m}=1.3$ (e.g. Werban et al., 2008). $\sigma_{\text {bulk-soil }}$, in the rhizotron also depends on the electrical conductivity of the nutrient solution $\left(\sigma_{w}\right)$ in the rhizotron used to grow plants. Measurements from suction cups indicate that $\sigma_{w}$ varies between 0.06 to $0.2 \mathrm{~S} / \mathrm{m}$ (Jougnot et al., 2012). We assume $\sigma_{w}$ to be $0.2 \mathrm{~S} / \mathrm{m}$ and choose $\mathrm{n}$ as 0.35 (sand) and 0.435 (loam), respectively, for calculating and comparing different pedophysical models. In the following sections, we will refer $\sigma_{\text {bulk-soil }}$ the soil bulk electrical conductivity (with $\sigma_{\text {bulk-loam }}$ and $\sigma_{\text {bulk-sand }}$ to specify soil type) when no roots are present and $\sigma_{\text {bulk }}$ will be used for studies or dataset where both roots and soil are present.

\subsection{Electrical modeling in EIDORS}

The ERT forward problem seeks apparent conductivity or voltage data by solving the Poisson's equation with appropriate boundary conditions with a known electrical conductivity distribution. In ERT inverse problem, we aim at reconstructing an estimate of the electrical conductivity distribution within the soil-root domain from apparent conductivity or voltage measurements at its boundary or at some discrete locations within the computational domain. The inverse problem finds an approximate $\sigma$-distribution that minimizes the data misfit between the virtual measurements and the model predictions in a least-square sense in addition to a regularization term. We use the finiteelement based software EIDORS (Adler and Lionheart, 2006) to solve the forward and inverse problems as it offers flexibility in using different meshing software such as NETGEN (Schöberl, 1997) and gmsh (Geuzaine and Remacle, 2009). The integration of such meshing software allows creating complex finite-element models for electrical conduction in a soil-root medium. The electrical conduction model for the rhizotron is in purely 2-D ( $x-z$ plane, $y=0)$. A point electrode model (Hanke et al., 2011) with a total number of 50 electrodes and a dipole-dipole measurement scheme is used to compute the forward response. All the electrodes are located at the boundary of the computational domain with a similar set-up as in Weigand and Kemna (2017). Three different finite-element meshes are used (Fig. 4). To simulate the ERT data set, the root growth simulation model mesh (SMDL), with an explicit representation of the root architecture is used. The ERT forward model mesh (FMDL), which does not contain the root architectural information, is used to compute the data misfit in the ERT inversion, and the ERT inverse mesh, a comparatively coarse mesh is used to compute the Jacobian in the ERT reconstruction. In the SMDL, either a $\sigma_{\text {root }}$ or $\sigma_{\text {bulk-soil }}(\theta)$ value is assigned to each element. The maize primary roots in our simulation have a 
mean thickness $(\sim 0.05 \mathrm{~cm})$ which is small compared to the dimensions of rhizotron $(20 \mathrm{x} 40 \mathrm{~cm})$, requiring a very high spatial resolution for roots in the SMDL.

To generate a root resolved mesh with high spatial resolution, first we created the binary images of root architectures at various ages (day 5, 7, 10, 12, 15, 18, 22, see Fig. 3). In these binary images, we removed extremely fine root hairs and root branches that were below $0.01 \mathrm{~cm}$ in thickness, assuming that such roots have negligible effect on the electric potential distribution. The simplified root image represent root branches with a mean diameter of $0.05 \mathrm{~cm}$. First, we convert binary image into a spline function that traces the boundary of the root surface (red lines in Fig. 4 b) using the boundary tracing function "bwboundaries" in MATLAB. The spline function representing the root shape was converted into finite element mesh using gmsh software. The root architecture mesh created in this manner possesses superior quality in terms of aspect ratio of elements and is computationally efficient. We then solved the electrical forward problem for the generated $\sigma$-map yielding virtual ERT data, which is subsequently inverted using EIDORS. For the inversion, first we generate a forward data set $\left(d_{1}\right)$ for a homogeneous $\sigma$-distribution $\left(\sigma_{1}=1 \mathrm{~S} / \mathrm{m}\right)$. Then the second forward data $d_{2}$ is computed using SMDL filled with $\sigma_{1}$ in addition to soil-root electrical conductivity distribution $\left(\sigma_{2}=\sigma_{1}+\sigma_{\text {bulk }}\right)$. A difference ERT inversion Gauss-Newton (GN) one step algorithm is used to estimate the change in the conductivity $\left(\delta \sigma=\sigma_{2}-\sigma_{1}\right)$ from the change in measurements $\left(\delta d=d_{2}-d_{1}\right)$ (Adler et al., 2007). The inversion is regularized using a Laplacian matrix. We assume a low noise data set and hence $\delta d$ is added with $1 \%$ random noise proportional to each measurement. The FMDL mesh is used to compute the ERT data $(\delta d)$ and the data misfit while the inverse mesh is used for the GN inversion.

\subsection{Computing average and effective electrical properties}

To get an insight on how a rooted soil might differ from bare soil pedophysical model (Eq. 2), we compare bulk electrical conductivity of soil-root medium, at two different scales: $2 \times 2 \mathrm{~cm}$ and $20 \mathrm{x}$ $40 \mathrm{~cm}$.

At smaller scale, the block-wise averaged data, denoted by $\left\langle\sigma_{b u l k}\right\rangle$ and $\langle\theta\rangle$ for electrical conductivity and water content respectively, are computed from averaging the corresponding data in the simulation model finite element mesh with an averaging block size of $2 \mathrm{~cm} \times 2 \mathrm{~cm}$ (see Fig. 7a). Averaging in each block is done by taking the arithmetic and the harmonic averages of conductivity data of all finite elements within each averaging block to get $\left\langle\sigma_{b u l k}\right\rangle$. The arithmetic 
averages assumes that the soil-root elements in each averaging block are connected in series while the harmonic mean assumes the elements to be in parallel. For $\langle\theta\rangle$, we computed only the arithmetic mean. In reality we expect, the real $\left\langle\sigma_{b u l k}\right\rangle$ to be in between the arithmetic and harmonic averages. The relation between the collection of averaged data points at every averaging block and at all time (day 5 to , i.e. $\langle\theta\rangle$ vs $\left\langle\sigma_{b u l k}\right\rangle$, will then approximately mimic the impact of roots at a block-scale on $\sigma_{\text {bulk }}$, when compared to the Archie's law applied in soils only (Eq.2).

At larger scale ( rhizotron scale, i.e. $20 \mathrm{~cm} \times 40 \mathrm{~cm}$ ), simple mean of arithmetic and harmonic averages over whole domain may not exactly represent bulk property, as we need to account the complex structural variations of electrical conductivity distributions and heterogeneity in soil electrical property. Hence, to compute $\sigma_{b u l k}$, at the scale of the rhizotron, we solve the Poisson's equation between two plate electrodes at the boundaries with root included (a root segment has its own electrical conductivity) and without root. The computation is repeated for two directions: in horizontal $\left(\sigma_{\text {bulkX }}\right)$ and vertical direction $\left(\sigma_{\text {bulkz }}\right)$. We included in our simulations, the plate electrodes that cover the entire left and right walls of the rhizotron as well as top and bottom wall of rhizotron and the ratio of injected current to measured voltage in these electrodes with the geometric factor considerations gives $\sigma_{b u l k Z}$ and $\sigma_{b u l k X}$.

\section{Results}

\subsection{Electrical measurements on Maize root segments}

Figure 5a shows the experimental data of $\sigma_{\text {root }}$ as a function of root age for Maize. We observe a gradual increase in $\sigma_{\text {root }}$ of intact maize root segments, as the segment distance from root collar increased (Fig. 5a). The trend is different in primary and brace roots, where the brace root conductivity increases much more rapidly with increasing distance of the segment from the root collar compared to primary root segments. The $\sigma_{\text {root }}$ also varies with respect to root cross-sectional area. Our measurements indicate that thinner roots have higher $\sigma_{\text {root }}$ compared to thicker roots (Fig. 5b). This could be due to higher water content of younger roots. Since we measured intact root segments, the surface electrical conductivity of endodermis and contact resistance of stele and cortex layers of the root are accounted in the measurements. The thicker outer layer (cortex) of the root is electrically more insulating than water rich younger roots or inner part (stele) as seen in early studies of Anderson et al. (1976). However, our measurements represent the combined resistivity of cortex and stele in an intact form. Age dependent electrical conductivity variations 
Biogeosciences Discuss., https://doi.org/10.5194/bg-2018-280

Manuscript under review for journal Biogeosciences

Discussion started: 5 July 2018

(c) Author(s) 2018. CC BY 4.0 License.

within a given species were earlier studied in poplar roots (Zenone et al., 2008). Fig. 5a shows that within the same species, in addition to age, different types of roots (brace and ground roots) can have different electrical properties. However, in the modeling work, we do not consider the development of brace roots as the simulated root system in the model is relatively young (3-weeks old). The blue-curve of Fig. 5a represents the data incorporated in our simulations: 0.0154 $<\sigma_{\text {root }}<0.03[\mathrm{~S} / \mathrm{m}]$.

\subsection{Virtual root simulation}

Simulations show that the relative SWC distribution patterns depend on the soil type (Figs. 6 a, b). After 22 days, the depletion is higher is the sand rhizotron as $\theta_{\mathrm{s}}$ is lower. In the loam, the soil is wetter and the contrast in saturation degree between the rooted and unrooted parts of the soil is much bigger.

When translated into electrical conductivity maps including the root electrical properties, we see different trends for sand and loam. For sand, we notice that $\sigma_{\text {root }}$ is always larger than $\sigma_{\text {bulk-sand }}$ and the difference between $\sigma_{\text {root }}$ and $\sigma_{\text {bulk-sand }}$ is always positive (Fig. 6c). For loam, however, we see that different regions where $\sigma_{\text {root }}{ }^{-} \sigma_{\text {bulk-loam }}$, contrast changes with time (Fig. 6d). At initial time, $\sigma_{\text {bulk-loam }}$ is larger than $\sigma_{\text {root }}$ but at day 18 , we see different regions, where the difference between $\sigma_{\text {root }}$ and $\sigma_{\text {bulk-loam }}$ is either positive, negative or close to zero. Such contrast does not manifest in sand. At day 22, in the upper portion of rhizotron, $\sigma_{\text {root }}$ is greater than $\sigma_{\text {bulk-loam }}$ whereas in the lower portion of rhizotron, the roots are masked by $\sigma_{\text {bulk-loam }}$ (see Fig. 6d). In real scenarios, i.e in any soil-root system, there potentially exist three regions, where the difference between $\sigma_{\text {root }}$ and $\sigma_{\text {bulk-soil }}$ is either positive, negative or close to zero. In our study, we observe that at low SWC, the mean of $\sigma_{\text {root }}$ is greater than the mean of $\sigma_{\text {bulk-loam }}$ and at high water content, the mean of $\sigma_{\text {root }}$ is lower than the mean of $\sigma_{\text {bulk-loam }}$, while in sand, the mean of $\sigma_{\text {root }}$ is nearly same as the mean of $\sigma_{\text {bulk-sand }}$ (Fig. 6e). Since electric current flow depends on the gradient of $\sigma$-distribution, the effect of roots in ERT experiments will be greater where there is higher $\sigma_{\text {root }}-\sigma_{\text {bulk-soil }}$ contrasts and most importantly, it is time dependent (Fig. 6e). In addition, the density of roots plays a role in terms of $\sigma_{\text {root }}-\sigma_{\text {bulk-soil }}$ contrasts, for instance at day 22 , the upper part of the root system is more conductive than $\sigma_{\text {bulk-loam }}$ in the upper part of the rhizotron and also reflects higher root volume than at initial times. Therefore, at later times (Fig. 6d, day 22), the ERT estimate of water content in the upper region could be misleading due to a stronger root influence on $\sigma_{\text {bulk }}$. 


\subsection{Bulk electrical properties}

The block wise averaged data shows that lower the root surface area, closer is the averaged data to the bare-soil pedophysical relation (Figs. $7 \mathrm{~b}$ and d). In sand, we see more difference between arithmetic and harmonic mean with harmonic mean staying closer to the original pedophysical curve than arithmetic mean (Fig. 7b). In loam, however, there is no big difference between arithmetic and harmonic block wise averaged data and both of them change the curvature of the pedophysical relation (Fig. 7d). As expected, when root density is high, the $\left\langle\theta>\right.$ vs $\left\langle\sigma_{\text {bulk }}>\right.$ plot significantly deviates from Eq. 2 and always overestimates $\sigma_{\text {bulk-sand }}$, whereas areas with very low to zero root density lie along $\sigma_{\text {bulk-soil }}(\theta)$ curve (blue dots on $\sigma_{\text {bulk-soil }}(\theta)$ curve for $\theta>0.2$ in Fig. $7 \mathrm{~b}$ and $\theta>0.3$ in Fig. 7d). In loam, the $\left\langle\theta>\right.$ vs $\left\langle\sigma_{\text {bulk }}>\right.$ points are scattered around the petrophysical relationship with a tendency of both overestimating $\sigma_{\text {bulk-loam }}$ for $\theta<0.2$ and underestimating $\sigma_{\text {bulk-loam }}$ for $\theta>0.2$ in the root dense region. This illustrates how roots might affect the relationship between SWC and $\sigma_{\text {bulk }}$.

At rhizotron scale, the effective bulk property shows significant anisotropic affect in sand (notice the difference between $\sigma_{\text {bulkX }}$ and $\sigma_{\text {bulkz }}$ in Fig. 7c). We expect that the dry sand act as a barrier to the electrical current flow, thereby decreasing the $\sigma_{\text {bulk }}$. The vertical direction has more pronounced anisotropy, when compared to horizontal direction $\left(\sigma_{b u l k X}>\sigma_{b u l k z}\right)$, as we see less deviation of $\sigma_{\text {bulkX }}$ from Eq. [2] when compared to $\sigma_{b u l k z}$. This is due to horizontal layering that develops in the electrical conductivity distribution due to root water uptake, which thereby affects current more in vertical direction than in horizontal direction. For loam medium, the anisotropic effect is less when compared to sand. We see from the effective bulk properties that the original pedophysical relation (Eq. [2]) would rather under-estimate the water content in loam where as it would over-estimate in sand (Fig.7 $\mathrm{c}$ and e). Computed $\sigma_{\text {bulkX }}$ and $\sigma_{\text {bulkz }}$ data points lie below $\sigma_{\text {bulk-soil }}(\theta)$ in sand medium whereas above in the loam medium. The rhizotron scale, bulk electrical conductivity deviates from Eq. [2] quite differently when compared to the averaged data at smaller scale. This can be understood as the impact of soil heterogeneity playing a bigger role in influencing the bulk property at large scale whereas at centimeter-scale $(2 \mathrm{~cm} \mathrm{x} 2 \mathrm{~cm})$, the root density plays a major role in the deviating the bulk property from bare soil pedophysical relation (Eq.[2]). 
Biogeosciences Discuss., https://doi.org/10.5194/bg-2018-280

Manuscript under review for journal Biogeosciences

Discussion started: 5 July 2018

(c) Author(s) 2018. CC BY 4.0 License.

Table 2 gives the computed anisotropy factor, $A F=\sigma_{b u l k X} / \sigma_{b u l k z}$ for cases with and without roots. As we can see from the table, the main anisotropic affect is due to soil heterogeneity and not the root themselves.

\subsection{ERT Inversion result}

The GN type ERT inversion was performed on the virtual measurement data set from the forward conductivity distribution with root system included (Figs. 8 a,d) and also without considering the root system. Figures $8 \mathrm{~b}$ and $8 \mathrm{e}$ shows the ERT inversion with root system included sand and loam medium, respectively. As we can see, the inversion works well in recovering most of the important features of soil water depletion, but sometimes we can observe contamination due to the presence of roots (for example day 18 and 22 in Fig. 8b). Note that for sand the presence of roots increased the electrical conductivity while for loam it decreased the electrical conductivity.

Figures $8 \mathrm{c}$ and $8 \mathrm{f}$ represents the difference in the inversion results of virtual data from forward conductivity distributions with and without root systems. The inversion result with roots is showed in Figs 8 ( $b$ and e) but the inversion results without considering the root system are not shown here. They were realized by inverting the apparent resistance data resulting from the conductivity distributions from soil water content map without the root electrical properties (but with the impact of the root system on the SWC and not in electrical conductivity map). This difference maps represent the impact of the roots on the ERT inverted $\sigma$-distributions (see Fig. $8 \mathrm{c}$ and f). In sand, the error in estimating the electrical conductivity corresponding to the water content of Eq. [2] can be as low as $2 \%$ when the roots are small and can reach up to $15 \%$ when soil becomes dry and roots occupy the whole rhizotron.

By comparing Figs. 8(a,b,c) and $8(\mathrm{~d}, \mathrm{e}, \mathrm{f})$, we can immediately see that in loam, the contrast between root and soil is low or the soil is more conductive than root at most time. Roots are like low conductive wires in the loam medium surrounded by highly conductive soil. Since $\sigma_{\text {bulk-loam }}$ dominates the effective properties, the impact of roots is also lower in loam compared to that of sand. At later time (Fig. 8d, day 22), as root water uptake becomes significant, the contrast between $\sigma_{\text {bulk-loam }}$ and $\sigma_{\text {root }}$ reduces making roots indistinguishable from soil. Figures $8 \mathrm{c}$ and $8 \mathrm{f}$ indicate that the error in the estimation of the conductivity /water content increases with ongoing root growth. While the error pattern is monotonic in sand increasing with root growth, in loam we see different regions of high and low error depending on soil-root contrast. These errors in $\sigma$-estimate manifest in the SWC estimated from Eq. [2]. We denote here, the volumetric average of water 
content from RSWMS simulation by: $\theta_{1}$, volumetric average of water content from ERT inverted $\sigma$-map without the root electrical properties in the ERT forward data by: $\theta_{2}$, and volumetric average of water content from ERT inverted $\sigma$-map with the root electrical properties included in the ERT forward data by: $\theta_{3}$. We show $\theta_{1}, \theta_{2}$ and $\theta_{3}$ as a function of time in Figure 9 (a,d). The difference between $\theta_{1}$ and $\theta_{2}$ is the error induced due ERT inversion procedure alone while the difference between $\theta_{1}$ and $\theta_{3}$ is the error induced due to ERT method as well as the root segments. In Figure 9 (b,c,e,f), we show that these errors in absolute and relative terms are more pronounced when the root system is large. When the root is young (age <10), the absolute error between $\theta_{1}$ and $\theta_{2}$ is same as the absolute error between $\theta_{1}$ and $\theta_{3}$ indicating that root segments has no significant impact in water content estimates (Fig. 9b and e).

\section{Conclusions}

We simulated an electrical conductivity model of a soil-root continuum in the rhizotron geometry. The roots were explicitly represented in the $\sigma$-distribution and root water uptake was simulated using mechanistic water flow models in soils and roots. We designed experiments on intact root segments to measure electrical properties of roots $\left(\sigma_{\text {root }}\right)$. Our measurements on maize root segments indicated that $\sigma_{\text {root }}$ is a function of distance from the root collar and root type (primary and brace roots). We incorporated the distance variations of primary roots into our model based on a polynomial fit.

Soil-root water flow modeling together with root electrical measurements reveals that soil-root electrical conductivity contrasts changes over time (Fig. 6) as a function of soil type and root water uptake. At centimeter-scale $(2 \mathrm{~cm} \times 2 \mathrm{~cm})$, the root play a major role in deviating $\sigma_{\text {bulk }}$ from Eq. [2]. Block-wise averaged data $\left(<\theta>\right.$ vs $\left\langle\sigma_{b u l k}\right\rangle$ ) shows that rooted soil deviates in terms of pedophysical relation from bare soil, where there is higher root density (Fig.7). This is consistent with the experimental observation made by Michot et al., (2016), where they found that bare-soil pedophysical relation is inadequate to explain $\sigma_{b u l k}(\theta)$ in the rooted zone. At decimeter scale, the $\sigma_{\text {bulk }}$ computed using plate electrode reveals anisotropy and different behavior as compared to the centimeter scale averaged data (see Fig. $7 \mathrm{~b}$ and c). We also observe an anisotropy factor of around six for fully mature root systems. This is mostly due to water content distribution pattern induced by root water uptake. At rhizotron scale, anisotropy is stronger in sand, when compared to loam, and increases non-linearly with root growth (Table 2). 
The GN type ERT inversion results (Figs. 8) reveal that exclusion of the explicit representation of roots in the forward model results in an error of 5 to $15 \%$ in $\sigma$. Even though the effect of roots at rhizotron scale is not evident in the bulk property analysis of conductivity data (table 2), it is evident in ERT inversion result. This indicates the importance of incorporating the effect of roots in the pedophysical model. The volumetric total water content shows a larger error for sandy soil (Fig.9). However, yet the overall trend of decrease in total water content due to root water uptake is recovered. The difference ERT inversion algorithm works well in recovering the overall structure of water uptake. For maize roots, the water uptake process dominates the $\sigma$-distribution of the soilroot system as reconstructed with ERT. It is also worth noting that there are various other root architectures such as tap root systems, which still need further investigations on their electrical anisotropy at rhizotron scale and at field scale.

The modeling results clearly show that, roots impacts ERT results. The degree of impact further depends on electrical conductivity contrast between root and soil. To characterize the specific impact of roots in ERT monitored water content estimates, we need the knowledge of electrical conductivity contrast between root and soil as a function of space and time. Estimating this contrast between root and soil, however, is not so straightforward and difficult, as they are root type, root age, root radius, soil type and water content dependent. Although the maize simulations in this study indicates that water content is the dominant factor affecting bulk electrical conductivity, other factors do play a role including the root connectivity that induces electrical anisotropy. Further upscaling the electrical properties derived from centimeter scale (root segment) to decimeter scale (rhizotron) to field scale ( 100 meter) is very important to develop a proper pedophysical relation that completely eliminates the root impact in the water content estimate.

Since our model indicates a non-negligible anisotropy factor in the electrical conductivity, ERT injection scheme should consider exploiting them to retrieve better information, for example, by having an injection scheme that maximizes the sensitivity in the region of anisotropy. Since anisotropy in $\sigma$ changes with development of the root system in soil, one could also have timedependent ERT injection schemes for the time-lapse ERT. A prior knowledge of time dependent electrical conductivity contrasts between soil and root, for a given crop, can definitely help in designing optimized ERT injection scheme for the future field experiments. 
Biogeosciences Discuss., https://doi.org/10.5194/bg-2018-280

Manuscript under review for journal Biogeosciences

Discussion started: 5 July 2018

(c) Author(s) 2018. CC BY 4.0 License.

Finally, we considered a very limited range in $\sigma_{\text {root }}-\sigma_{\text {bulk-soil }}$ variability. In reality, the range of variations in $\sigma_{\text {root }}-\sigma_{\text {bulk-soil }}$ could differ depending on the type of roots and the value of $\sigma_{w}$ (Fig.1). As in agricultural fields, even in two-dimensional rhizotron experiments, air filled cracks can manifest in the soil, potentially influencing ERT measurements. In our model, we did not consider such real-world phenomena and limited our study only to the impact of roots. We also ignored rhizosphere processes such as root exudation, which could affect the water content estimates. In reality, soil-root systems are three-dimensional structures and two-dimensional rhizotron approximations may not represent an accurate model for three-dimensional electrical conductivity in real soil-root environments (e.g. cropped fields). We also ignored the anisotropy of $\sigma$ inside the root structure (stele-cortex variations), which may have a considerable effect on ERT measurements. Such structural variations may induce even higher degree of anisotropy in the electrical conductivity. Our next step will be the validation of our findings in real experiments and under even more realistic conditions, accounting, amongst other aspects, for the specific rhizosphere properties, and to extend the studies to include complex conductivity (induced polarization) properties.

\section{References}

Adler, A. and Lionheart, W. R. B.: Uses and abuses of EIDORS: an extensible software base for EIT, Physiological Measurement, 27(5), S25, 2006.

Adler, A., Dai, T. and Lionheart, W. R. B.: Temporal image reconstruction in electrical impedance tomography, Physiol. Meas., 28(7), S1, doi:10.1088/0967-3334/28/7/S01, 2007.

Al Hagrey, S. A.: Geophysical imaging of root-zone, trunk, and moisture heterogeneity, Journal of Experimental Botany, 58(4), 839-854, doi:10.1093/jxb/erl237, 2007.

Al Hagrey, S. A. and Petersen, T.: Numerical and experimental mapping of small root zones using optimized surface and borehole resistivity tomography, Geophysics, 76(2), G25-G35, doi:10.1190/1.3545067, 2011.

Amato, M., Bitella, G., Rossi, R., Gómez, J. A., Lovelli, S. and Gomes, J. J. F.: Multi-electrode 3D resistivity imaging of alfalfa root zone, European Journal of Agronomy, 31(4), 213-222, doi:10.1016/j.eja.2009.08.005, 2009.

Amente, G., Baker, J. M. and Reece, C. F.: Estimation of Soil Solution Electrical Conductivity from Bulk Soil Electrical Conductivity in Sandy Soils, Soil Science Society of America Journal, 64(6), 1931-1939, doi:10.2136/sssaj2000.6461931x, 2000.

Anderson, W. P. and Higinbotham, N.: Electrical Resistances of Corn Root Segments, Plant Physiology, 57(2), 137-141, 1976. 
Biogeosciences Discuss., https://doi.org/10.5194/bg-2018-280

Manuscript under review for journal Biogeosciences

Discussion started: 5 July 2018

(c) Author(s) 2018. CC BY 4.0 License.

Archie, G. E.: The Electrical Resistivity Log as an Aid in Determining Some Reservoir Characteristics, SPE942054-G, doi:10.2118/942054-G, 1942.

Beff, L., Günther, T., Vandoorne, B., Couvreur, V. and Javaux, M.: Three-dimensional monitoring of soil water content in a maize field using Electrical Resistivity Tomography, Hydrol. Earth Syst. Sci., 17(2), 595609, doi:10.5194/hess-17-595-2013, 2013.

Bhatt, S. and Jain, P. K.: Correlation between electrical resistivity and water content of sand - a statistical approach, Am. Int. J. of Res. in Sci., Tech., Eng. \& Math., 6(2), 115-121, 2014.

Brillante, L., Bois, B., Lévêque, J. and Mathieu, O.: Variations in soil-water use by grapevine according to plant water status and soil physical-chemical characteristics-A 3D spatio-temporal analysis, European Journal of Agronomy, 77, 122-135, doi:10.1016/j.eja.2016.04.004, 2016.

Brovelli, A. and Cassiani, G.: Combined estimation of effective electrical conductivity and permittivity for soil monitoring, Water Resour. Res., 47(8), W08510, doi:10.1029/2011WR010487, 2011.

Cao, Y., Repo, T., Silvennoinen, R., Lehto, T. and Pelkonen, P.: An appraisal of the electrical resistance method for assessing root surface area, Journal of Experimental Botany, 61(9), 2491-2497, doi:10.1093/jxb/erq078, 2010.

Cao, Y., Repo, T., Silvennoinen, R., Lehto, T. and Pelkonen, P.: Analysis of the willow root system by electrical impedance spectroscopy, Journal of Experimental Botany, 62(1), 351-358, doi:10.1093/jxb/erq276, 2011.

Couvreur, V., Vanderborght, J. and Javaux, M.: A simple three-dimensional macroscopic root water uptake model based on the hydraulic architecture approach, Hydrol. Earth Syst. Sci., 16(8), 2957-2971, doi:10.5194/hess-16-2957-2012, 2012.

De Carlo, L., Battilani, A., Solimando, D., Battilani, A., Lo Porto, A. and Caputo, M. C.: Monitoring different irrigation strategies using surface ERT, pp. 71-75. [online] Available from: https://www.scopus.com/inward/record.uri?eid=2-s2.084957960460\&partnerID=40\&md5=d5a2e82335284345a7097045eaaad93b, 2015.

de Dorlodot, S., Forster, B., Pagès, L., Price, A., Tuberosa, R. and Draye, X.: Root system architecture: opportunities and constraints for genetic improvement of crops, Trends in Plant Science, 12(10), 474481, doi:10.1016/j.tplants.2007.08.012, 2007.

Doussan, C., Pierret, A., Garrigues, E. and Pagès, L.: Water Uptake by Plant Roots: II - Modelling of Water Transfer in the Soil Root-system with Explicit Account of Flow within the Root System - Comparison with Experiments, Plant Soil, 283(1-2), 99-117, doi:10.1007/s11104-004-7904-z, 2006.

Ehosioke, S., Sarah Garré, Kremer, T., Rao, S., Kemna, A., Huisman, J., Zimmermann, E., Javaux, M. and Nguyen, F.: A NEW METHOD FOR CHARACTERIZING THE COMPLEX ELECTRICAL PROPERTIES OF ROOT SEGMENTS, n.d.

Friedman, S. P.: Soil properties influencing apparent electrical conductivity: a review, Computers and Electronics in Agriculture, 46(1-3), 45-70, doi:10.1016/j.compag.2004.11.001, 2005. 
Biogeosciences Discuss., https://doi.org/10.5194/bg-2018-280

Manuscript under review for journal Biogeosciences

Discussion started: 5 July 2018

(c) Author(s) 2018. CC BY 4.0 License.

Garrè, S., Javaux, M., Vanderborght, J., Pagès, L. and Vereecken, H.: Three-Dimensional Electrical Resistivity Tomography to Monitor Root Zone Water Dynamics, Vadose Zone Journal, 10(1), 412-424, doi:10.2136/vzj2010.0079, 2011.

van Genuchten, M. T.: CLOSED-FORM EQUATION FOR PREDICTING THE HYDRAULIC CONDUCTIVITY OF UNSATURATED SOILS., Soil Science Society of America Journal, 44(5), 892-898, 1980.

Geuzaine, C. and Remacle, J.-F.: Gmsh: A 3-D finite element mesh generator with built-in pre- and postprocessing facilities, International Journal for Numerical Methods in Engineering, 79(11), 1309-1331, doi:10.1002/nme.2579, 2009.

Ginsburg, H. and Laties, G. G.: Longitudinal electrical resistance of maize roots, Journal of Experimental Botany, 24(6), 1035-1040, doi:10.1093/jxb/24.6.1035, 1973.

Hanke, M., Harrach, B. and Hyvönen, N.: Justification of point electrode models in electrical impedance tomography, Math. Models Methods Appl. Sci., 21(06), 1395-1413, doi:10.1142/S0218202511005362, 2011.

Javaux, M., Schröder, T., Vanderborght, J. and Vereecken, H.: Use of a three-dimensional detailed modeling approach for predicting root water uptake, Vadose Zone Journal, 7(3), 1079-1088, doi:10.2136/vzj2007.0115, 2008.

Jougnot, D., Linde, N., Revil, A. and Doussan, C.: Derivation of soil-specific streaming potential electrical parameters from hydrodynamic characteristics of partially saturated soils, Vadose Zone Journal, 11(1), 0, doi:10.2136/vzj2011.0086, 2012.

Laloy, E., Javaux, M., Vanclooster, M., Roisin, C. and Bielders, C. L.: Electrical Resistivity in a Loamy Soil: Identification of the Appropriate Pedo-Electrical Model, Vadose Zone Journal, 10(3), 1023-1033, doi:10.2136/vzj2010.0095, 2011.

Lobet, G., Pagès, L. and Draye, X.: A Novel Image-Analysis Toolbox Enabling Quantitative Analysis of Root System Architecture, Plant Physiol., 157(1), 29-39, doi:10.1104/pp.111.179895, 2011.

Michot, D., Benderitter, Y., Dorigny, A., Nicoullaud, B., King, D. and Tabbagh, A.: Spatial and temporal monitoring of soil water content with an irrigated corn crop cover using surface electrical resistivity tomography, Water Resources Research, 39(5), SBH141-SBH1420, 2003.

Michot, D., Thomas, Z. and Adam, I.: Nonstationarity of the electrical resistivity and soil moisture relationship in a heterogeneous soil system: a case study, SOIL, 2(2), 241-255, doi:10.5194/soil-2-2412016, 2016.

Paglis, C. M.: Application of Electrical Resistivity Tomography for Detecting Root Biomass in Coffee Trees, International Journal of Geophysics, doi:10.1155/2013/383261, 2013.

Rossi, R., Amato, M., Bitella, G., Bochicchio, R., Ferreira Gomes, J. J., Lovelli, S., Martorella, E. and Favale, P.: Electrical resistivity tomography as a non-destructive method for mapping root biomass in an orchard, European Journal of Soil Science, 62(2), 206-215, doi:10.1111/j.1365-2389.2010.01329.x, 2011. 
Biogeosciences Discuss., https://doi.org/10.5194/bg-2018-280

Manuscript under review for journal Biogeosciences

Discussion started: 5 July 2018

(c) Author(s) 2018. CC BY 4.0 License.

Schöberl, J.: An advancing front 2D/3D-mesh generator based on abstract rules, Computing and Visualization in Science, 1(1), 41-52, doi:10.1007/s007910050004, 1997.

Srayeddin, I. and Doussan, C.: Estimation of the spatial variability of root water uptake of maize and sorghum at the field scale by electrical resistivity tomography, Plant Soil, 319(1-2), 185-207, doi:10.1007/s11104-008-9860-5, 2009.

Tournier, P.-H., Hecht, F. and Comte, M.: Finite Element Model of Soil Water and Nutrient Transport with Root Uptake: Explicit Geometry and Unstructured Adaptive Meshing, Transport in Porous Media, 106(2), 487-504, doi:10.1007/s11242-014-0411-7, 2015.

Vanella, D., Cassiani, G., Busato, L., Boaga, J., Barbagallo, S., Binley, A. and Consoli, S.: Use of small scale electrical resistivity tomography to identify soil-root interactions during deficit irrigation, Journal of Hydrology, 556, 310-324, doi:10.1016/j.jhydrol.2017.11.025, 2018.

Waxman, M. H. and Smits, L. J. M.: Electrical Conductivities in Oil-Bearing Shaly Sands, SPE-1863-A, doi:10.2118/1863-A, 1968.

Werban, U., Al Hagrey, S. A. and Rabbel, W.: Monitoring of root-zone water content in the laboratory by 2D geoelectrical tomography, Journal of Plant Nutrition and Soil Science, 171(6), 927-935, doi:10.1002/jpln.200700145, 2008.

Whalley, W. R., Binley, A., Watts, C. W., Shanahan, P., Dodd, I. C., Ober, E. S., Ashton, R. W., Webster, C. P., White, R. P. and Hawkesford, M. J.: Methods to estimate changes in soil water for phenotyping root activity in the field, , doi:10.1007/s11104-016-3161-1, 2017.

Wilderotter, O.: An adaptive numerical method for the Richards equation with root growth, Plant and Soil, 251(2), 255-267, doi:10.1023/A:1023031924963, 2003.

Wunderlich, T., Petersen, H., al Hagrey, S. A. and Rabbel, W.: Pedophysical models for resistivity and permittivity of partially water-saturated soils, Vadose Zone Journal, 12(4), doi:10.2136/vzj2013.01.0023, 2013.

Zenone, T., Morelli, G., Teobaldelli, M., Fischanger, F., Matteucci, M., Sordini, M., Armani, A., Ferrè, C., Chiti, T. and Seufert, G.: Preliminary use of ground-penetrating radar and electrical resistivity tomography to study tree roots in pine forests and poplar plantations, Functional plant biology FPB [online] Available from: http://agris.fao.org/agris-search/search.do?recordID=US201301559026 (Accessed 14 September 2017), 2008. 
Biogeosciences Discuss., https://doi.org/10.5194/bg-2018-280

Manuscript under review for journal Biogeosciences

Discussion started: 5 July 2018

(c) Author(s) 2018. CC BY 4.0 License.

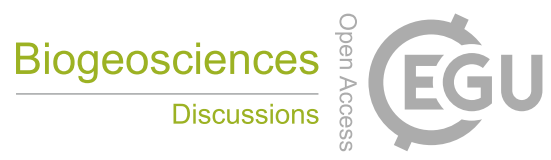

(c) (1)

568

569

570

571

572

573

574

575

576

577

578

579

580

581

582

583

584

585

586

587

588

\section{Tables:}

\begin{tabular}{|l|l|l|l|l|l|l|}
\hline & $\theta r\left[\mathrm{~cm}^{3} \mathrm{~cm}^{-3}\right]$ & $\theta s\left[\mathrm{~cm}^{3} \mathrm{~cm}^{-3}\right]$ & $a[1 / \mathrm{cm}]$ & $n$ & $K s[\mathrm{~cm} /$ day $]$ & $\lambda$ \\
\hline Sand & 0 & 0.35 & 0.05 & 2 & 100.24 & 0.5 \\
\hline Loam & 0.078 & 0.435 & 0.036 & 1.56 & 25 & 0.6 \\
\hline
\end{tabular}

Table 1: Soil hydraulic properties. $\theta r$ : Residual water content, $\theta s$ : Saturated water content, $a, n$ and $\lambda$ : shape parameters in van Genuchten-Mualem equations, $K s$ : saturated soil hydraulic conductivity. 
Biogeosciences Discuss., https://doi.org/10.5194/bg-2018-280

Manuscript under review for journal Biogeosciences

Discussion started: 5 July 2018

(c) Author(s) 2018. CC BY 4.0 License.

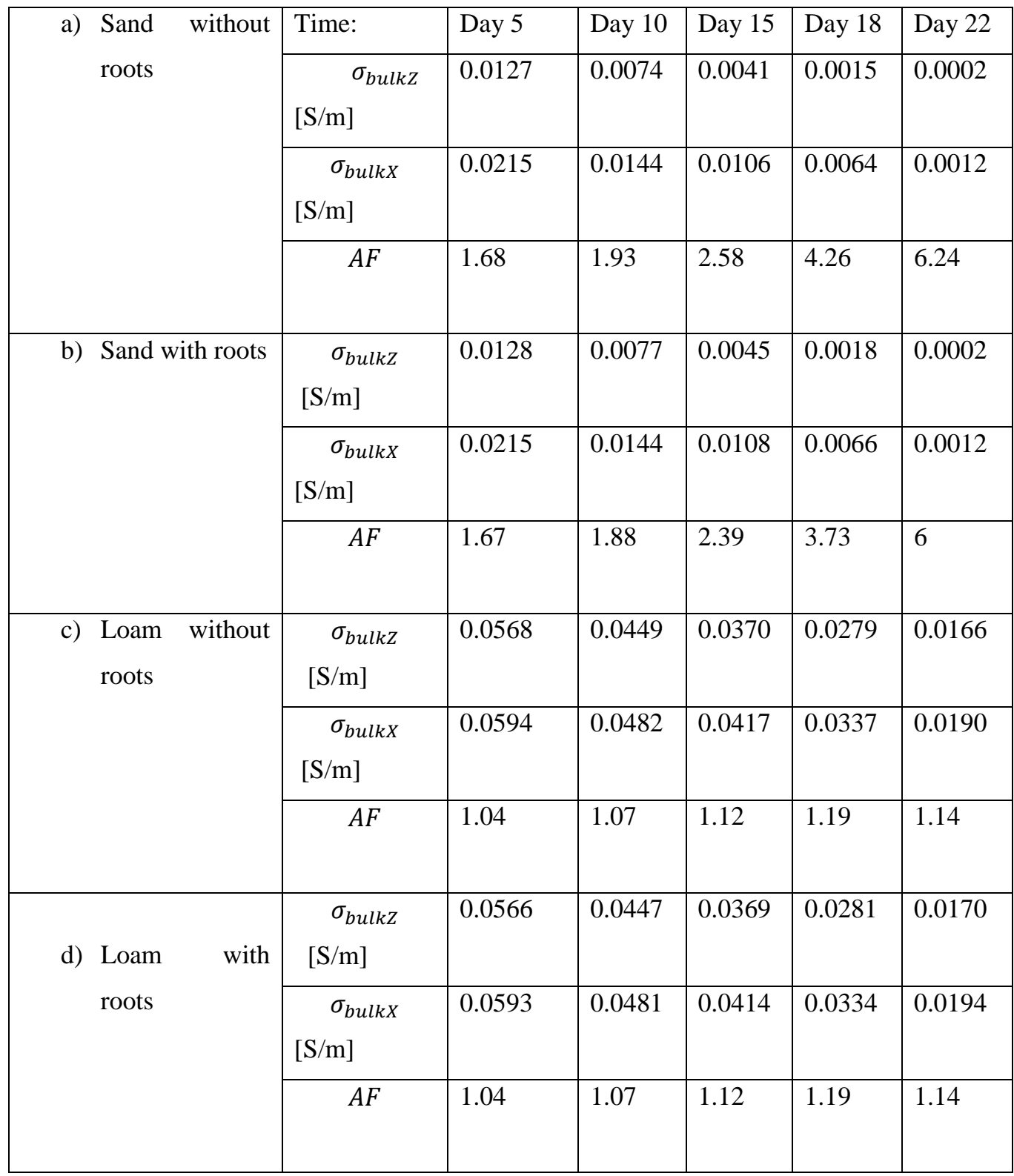

589

590

591

592

593

594

Table 2: Effective electrical conductivity in $[\mathrm{S} / \mathrm{m}]$ and anisotropy factor at rhizotron scale computed using simulated plate electrodes at boundaries. 
Biogeosciences Discuss., https://doi.org/10.5194/bg-2018-280

Manuscript under review for journal Biogeosciences

Discussion started: 5 July 2018

(c) Author(s) 2018. CC BY 4.0 License.

Figures:

596

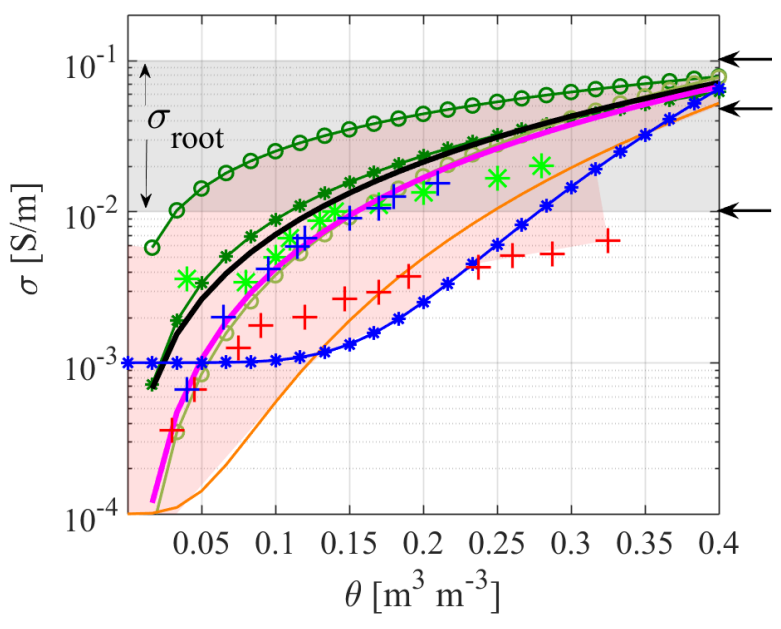

$\sigma_{\text {Willow grass }}($ Cao et al.,2010)

$\sigma_{\text {Zea maize }}$ (Anderson and Higinbotham,1976)

597

598 Figure 1. Comparison of soil and root electrical conductivity. The envelops of $\sigma_{\text {soil }}$ (some with and some without roots) and $\sigma_{\text {root }}$ are shown as shaded areas.

600

601

602 
Biogeosciences Discuss., https://doi.org/10.5194/bg-2018-280

Manuscript under review for journal Biogeosciences

Discussion started: 5 July 2018

(c) Author(s) 2018. CC BY 4.0 License.

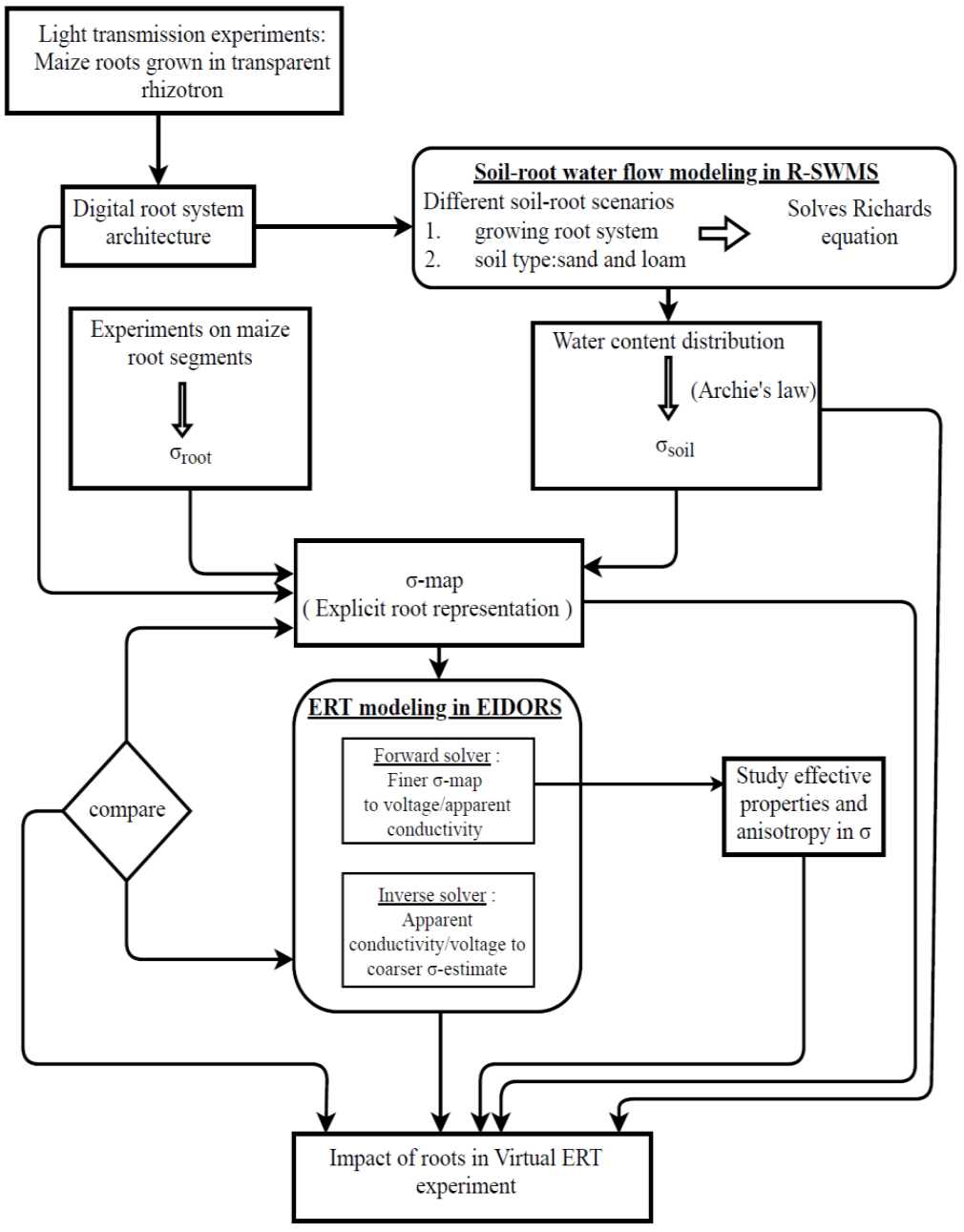

604 Figure 2: Flow chart for the simulation of Virtual Rhizotron drying experiment. First, a 605 simulation of root water uptake and root growth of a maize plant in a rhizotron is run with a soil606 plant water flow model (RSWMS, Javaux et al., 2008), which generates maps of soil water distribution $(\theta)$ and of root architecture evolution. Then these distributions are transformed into detailed electrical conductivity $(\sigma)$ maps through bio/pedo-physical relations. Third, these distributions are used to simulate a virtual ERT measurement and inversion scheme to get a coarser distribution of $\sigma$ estimates (see text for further details). 
Biogeosciences Discuss., https://doi.org/10.5194/bg-2018-280

Manuscript under review for journal Biogeosciences

Discussion started: 5 July 2018

(c) Author(s) 2018. CC BY 4.0 License.

(c) (i)

611

612 Figure 3: root architectural evolution shown at different times.

613

614

615

616

617

618

619

620
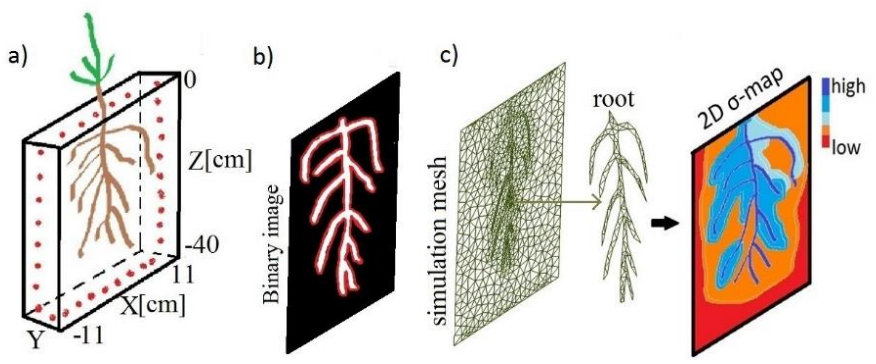
and e) regular uniform grid used to simulate Richards' equation.
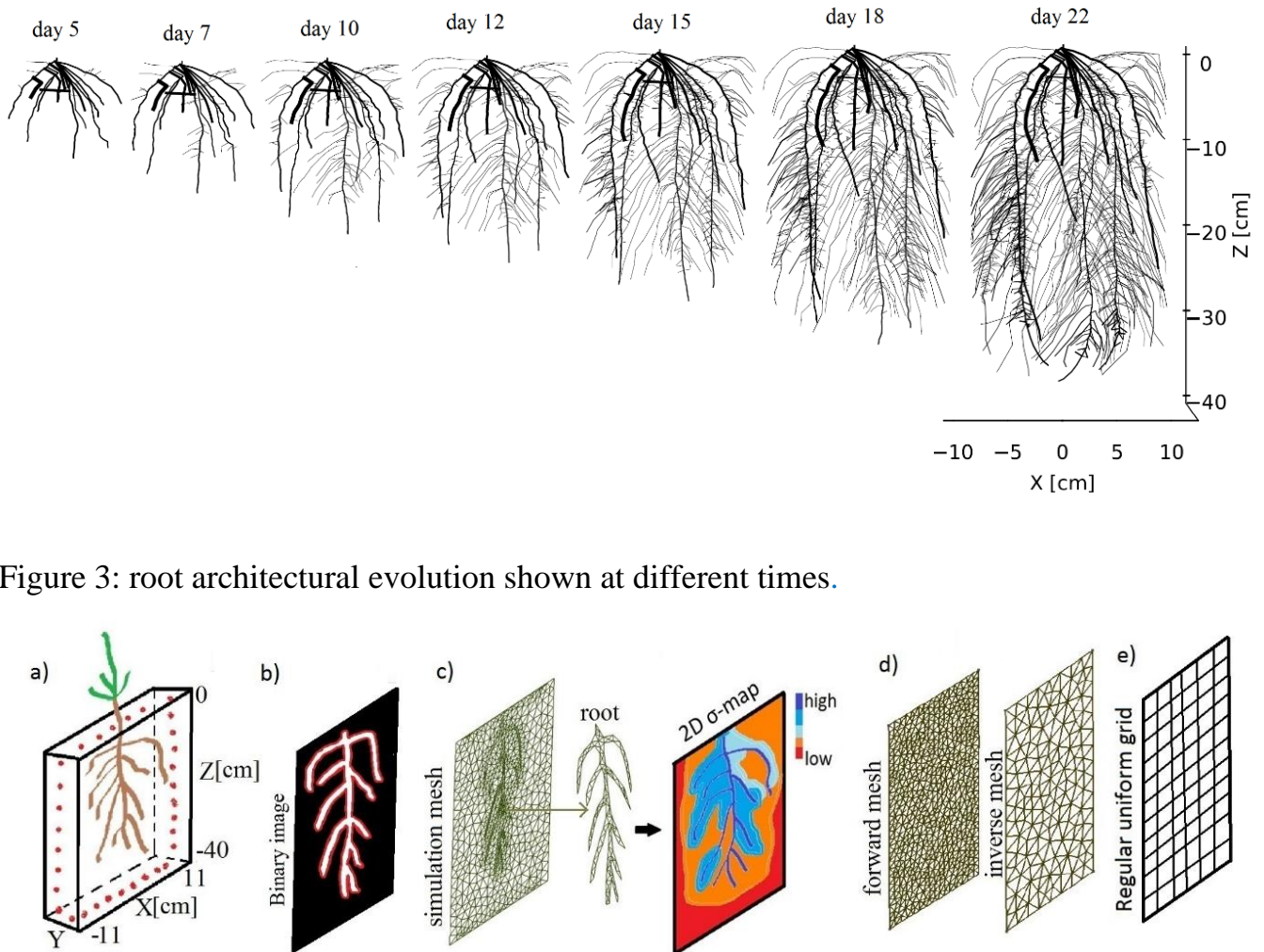

Figure 4: a) Virtual rhizotron schematic, b) binary image of schematic root architecture used to generate mesh. The red region represents the spline curve that envelops the root surface. c) Simulation model (SMDL): simulation mesh with explicit root architecture and schematic conductivity distribution map, d) forward model (FMDL): forward and inverse mesh, 


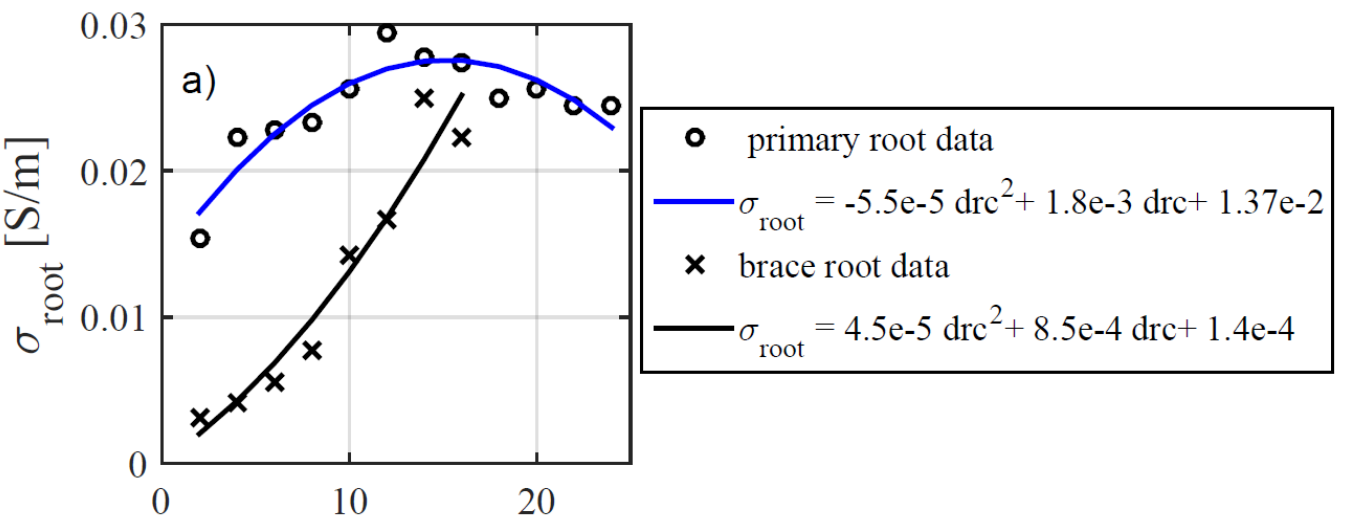

distance from root collar

$(\mathrm{drc})[\mathrm{cm}]$

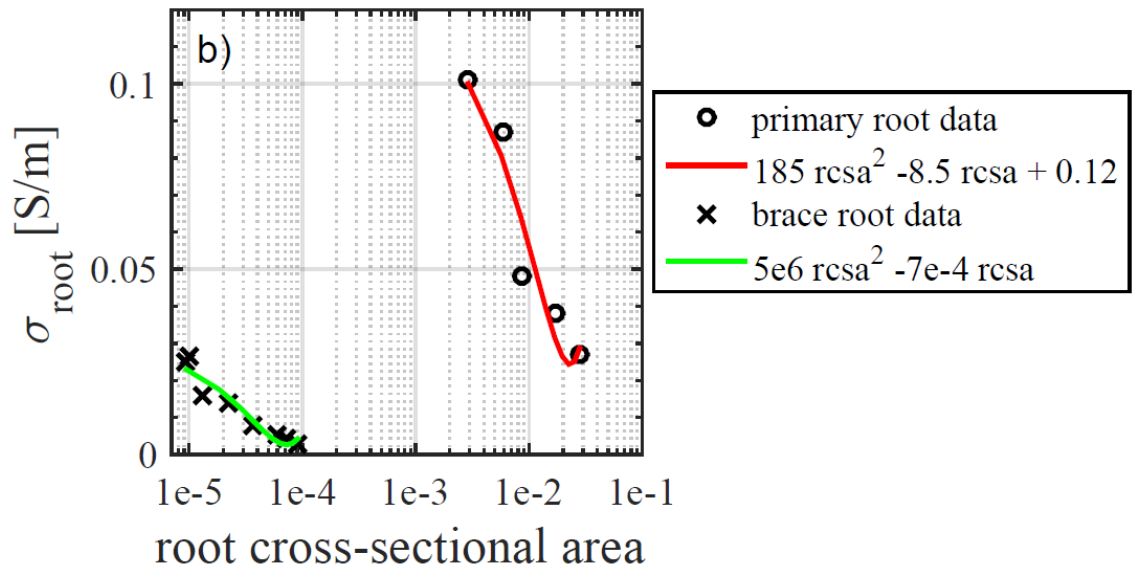

(rcsa) $\left[\mathrm{cm}^{2}\right]$

622 Figure 5: Measurement data on Maize roots a) $\sigma_{\text {root }}$ vs distance from root collar, b) $\sigma_{\text {root }}$ vs root

623 cross sectional area. The quadratic fit is shown as solid line while measurement data is 624 represented at discrete locations as circles (primary root) and crosses (brace root). The blue curve in Figure 5a is the data used in simulation model. 
Biogeosciences Discuss., https://doi.org/10.5194/bg-2018-280

Manuscript under review for journal Biogeosciences

Discussion started: 5 July 2018

(c) Author(s) 2018. CC BY 4.0 License.
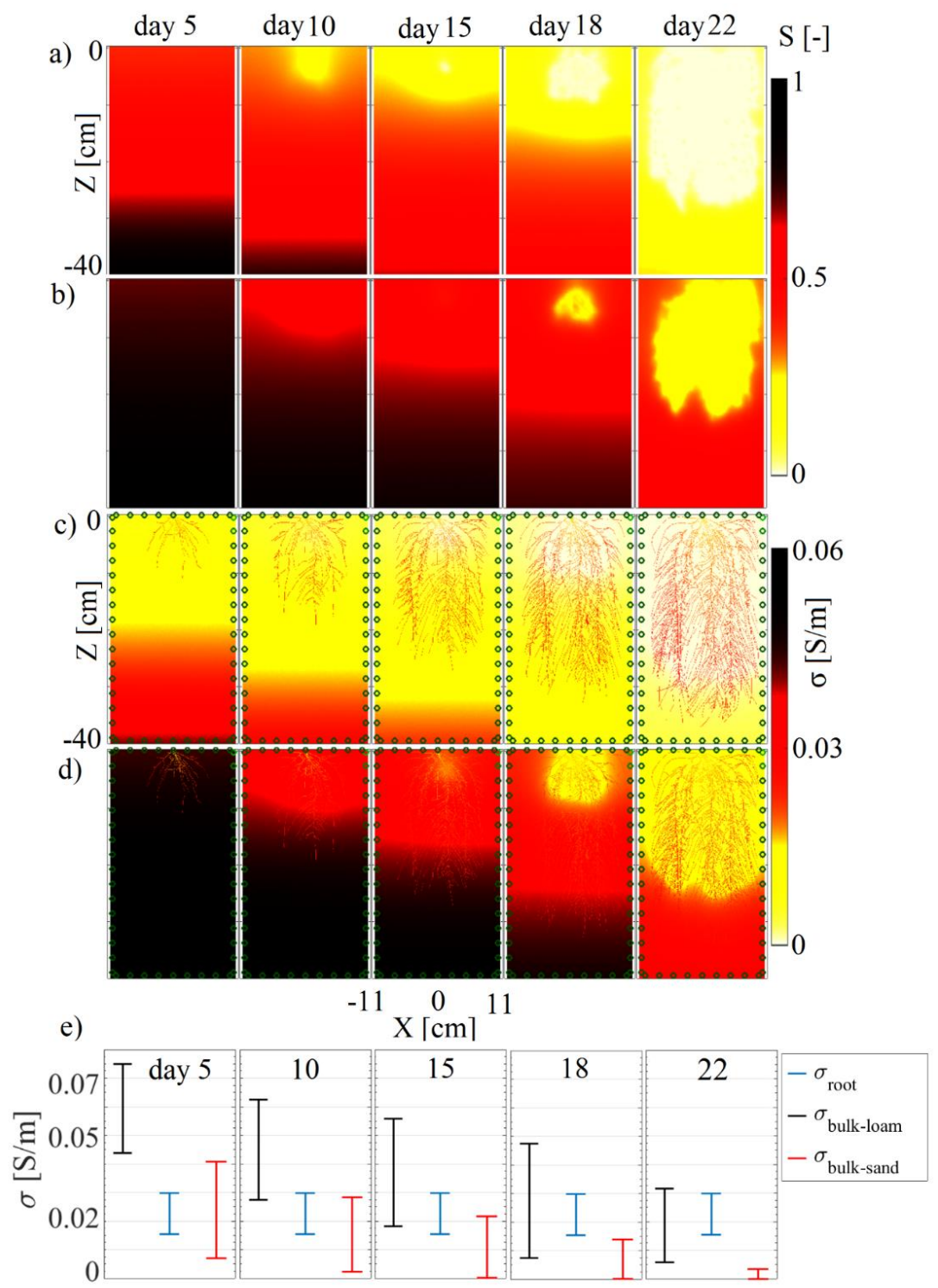

627 Figure 6: Volumetric water saturation distribution in a) sand and b) loam, and its corresponding $628 \sigma$-maps in c) sand and d) loam, e) variability of $\sigma$ in the rhizotron at different times. The vertical bars at various times represent the minimum and maximum value of $\sigma$, respectively. 
Biogeosciences Discuss., https://doi.org/10.5194/bg-2018-280

Manuscript under review for journal Biogeosciences

Discussion started: 5 July 2018

(c) Author(s) 2018. CC BY 4.0 License.
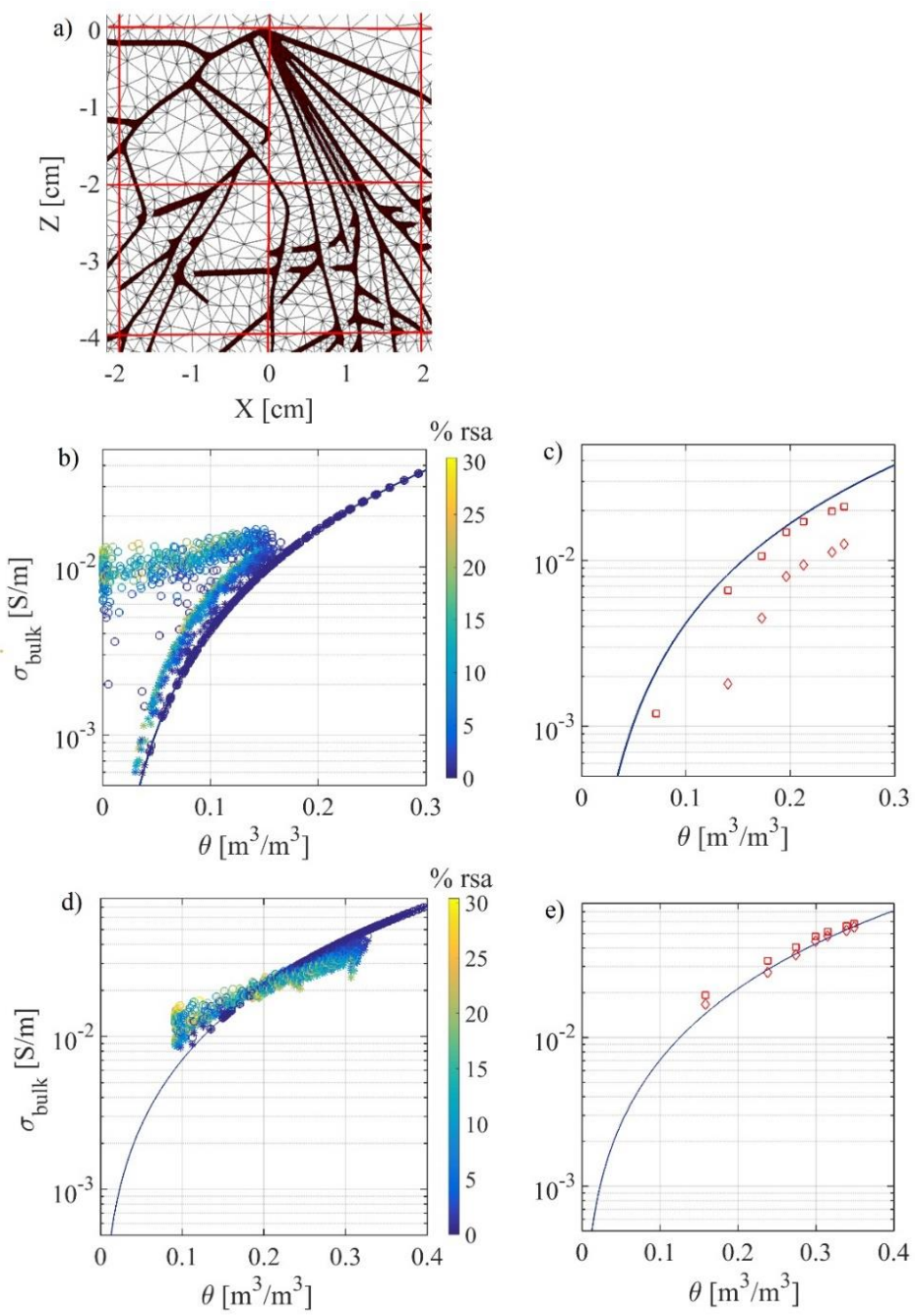

Figure 7: a) A section of the SMDL mesh with averaging blocks shown in red squares. The root

632 elements are in brown color, b) Comparison of Eq. [2] with block-wise averaged quantities $633\left(<\sigma_{\text {bulk }}\right\rangle$ vs. $\left.<\theta>\right)$ in sand, c) Comparison of Eq. [2] with rhizotron scale effective bulk property 634 in sand, d) Comparison of Eq. [2] with block-wise averaged quantities ( $\left\langle\sigma_{b u l k}\right\rangle$ vs. $\langle\theta\rangle$ ) in loam, c) Comparison of Eq. [2] with rhizotron scale effective bulk property in loam. 
Biogeosciences Discuss., https://doi.org/10.5194/bg-2018-280

Manuscript under review for journal Biogeosciences

Discussion started: 5 July 2018

(c) Author(s) 2018. CC BY 4.0 License.

a)

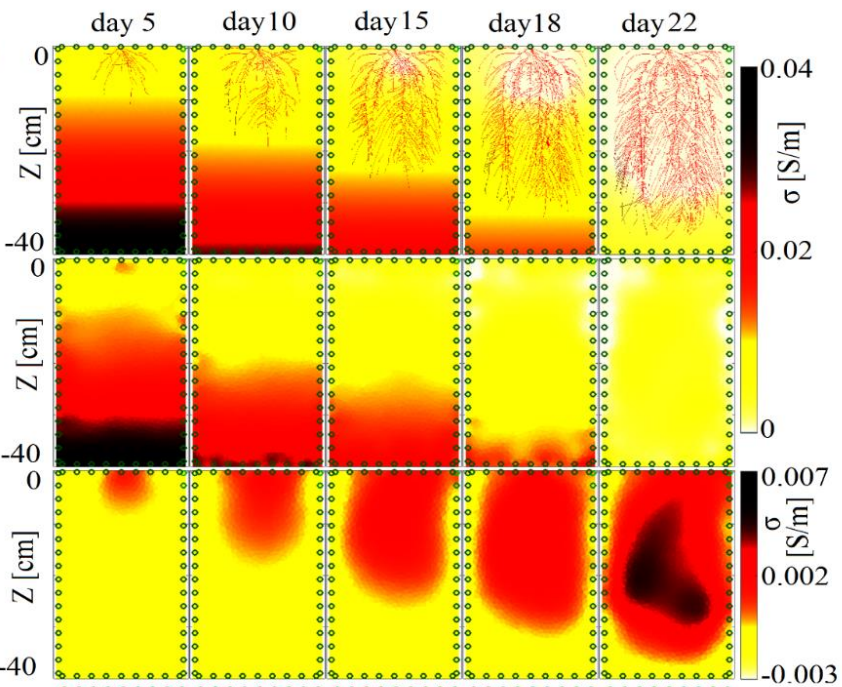

d)

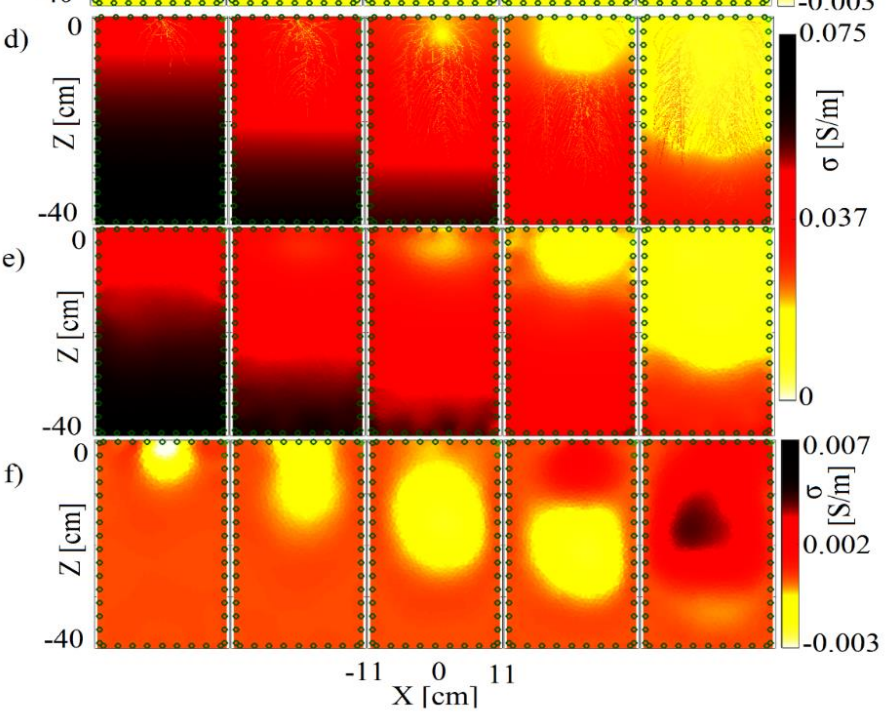

638

Figure 8: Sand: a) detailed electrical conductivity map of maize root at different times; b) tomography inversion with the root conductivity included in the forward model; c) difference between the inversions results with and without root conductivity accounted for in the forward model. Green circles represent the electrode positions. Loam: d) Conductivity map of maize root at different time; e) tomography inversion with the root conductivity included in the forward model; f) difference between the inversions results with and without root conductivity in the forward model. 
Biogeosciences Discuss., https://doi.org/10.5194/bg-2018-280

Manuscript under review for journal Biogeosciences

Discussion started: 5 July 2018

(c) Author(s) 2018. CC BY 4.0 License.

645

646

647

648

649

650

651 b)
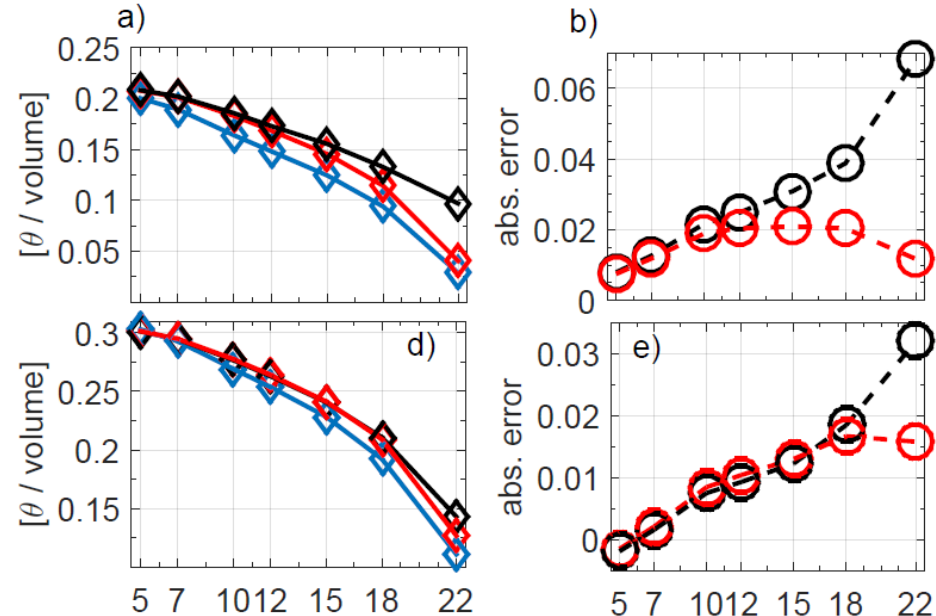

time [days]

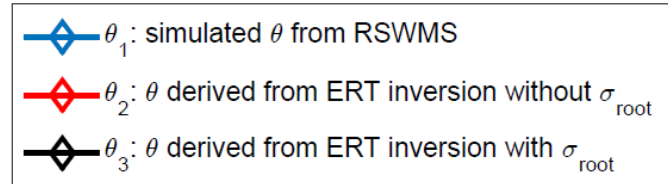

- $-\theta_{3}-\theta_{1}$

$-\bigodot=\theta_{2}-\theta_{1}$ c)
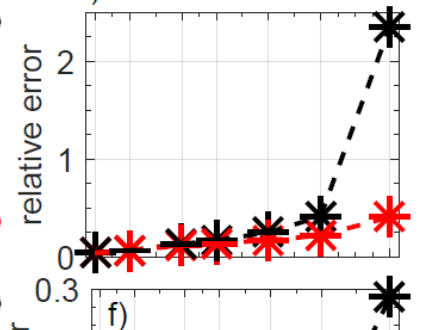

$\div \quad \mathrm{f}$

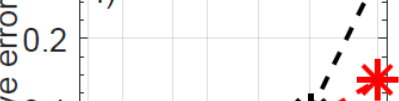

$\geq 0.1$

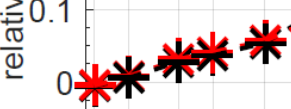

$5710121518 \quad 22$

一米- $\left(\theta_{3}-\theta_{1}\right) / \theta_{1}$
- 沗- $\left(\theta_{2}-\theta_{1}\right) / \theta_{1}$

Figure 9: a) Comparison of normalized volume averaged water content, obtained from simulated SWC (denoted as $\theta_{1}$ ) and ERT imaging without and with inclusion of $\sigma_{\text {root }}$ denoted by $\theta_{2}$ and $\theta_{3}$, respectively as a function of different root growth time in sand, b) Absolute error between $\left(\theta_{1}, \theta_{3}\right)$ and $\left.\left(\theta_{1}, \theta_{2}\right), \mathrm{c}\right)$ relative error between $\left(\theta_{1}, \theta_{3}\right)$ and $\left(\theta_{1}, \theta_{2}\right)$. Figures $9(\mathrm{~d}, \mathrm{e}, \mathrm{f})$ same as 9 $(a, b, c)$ but in loam medium. 